\title{
Too much of a good thing: why it is bad to stimulate the beta cell to secrete insulin
}

\author{
K. Aston-Mourney • J. Proietto • G. Morahan • \\ S. Andrikopoulos
}

Received: 30 November 2007 / Accepted: 7 January 2008 / Published online: 2 February 2008

(C) Springer-Verlag 2008

\begin{abstract}
In many countries, first- or second-line pharmacological treatment of patients with type 2 diabetes consists of sulfonylureas (such as glibenclamide [known as glyburide in the USA and Canada]), which stimulate the beta cell to secrete insulin. However, emerging evidence suggests that forcing the beta cell to secrete insulin at a time when it is struggling to cope with the demands of obesity and insulin resistance may accelerate its demise. Studies on families with persistent hyperinsulinaemic hypoglycaemia of infancy (PHHI), the primary defect of which is hypersecretion of insulin, have shown that overt diabetes can develop later in life despite normal insulin sensitivity. In addition, in vitro experiments have suggested that reducing insulin secretion from islets isolated from patients with diabetes can restore insulin pulsatility and improve function. This article will explore the hypothesis that forcing the beta cell to hypersecrete insulin may be counterproductive and lead to dysfunction and death via mechanisms that may involve the endoplasmic reticulum and oxidative stress. We suggest that, in diabetes, therapeutic approaches should be targeted towards relieving the demand on the beta cell to secrete insulin.
\end{abstract}

K. Aston-Mourney $\cdot$ J. Proietto $\cdot$ S. Andrikopoulos $(\bowtie)$

The University of Melbourne Department of Medicine (AH/NH),

Heidelberg Repatriation Hospital,

Building 24, 300 Waterdale Road,

Heidelberg Heights VIC 3081, Australia

e-mail: sof@unimelb.edu.au

G. Morahan

Centre for Diabetes Research,

Western Australian Institute for Medical Research,

University of Western Australia,

Crawley, WA, Australia
Keywords C57BL/6 $\cdot$ DBA/2 $\cdot$ Endoplasmic reticulum stress · Hypersecretion · Hyperinsulinaemia · Insulin · Islet dysfunction · Oxidative stress
Abbreviations
ER endoplasmic reticulum
NNT nicotinamide nucleotide transhydrogenase
PERK RNA-dependent protein kinase-like ER kinase
PHHI persistent hyperinsulinaemic hypoglycaemia of infancy
ROS reactive oxygen species

\section{Insulin hypersecretion, beta cell dysfunction and diabetes}

Type 2 diabetes is the result of two defects: insulin resistance in peripheral tissues (predominantly muscle, fat and liver), and islet beta cell dysfunction causing reduced insulin secretion. Insulin resistance, whether induced or genetic, may be the initiating defect, which in the first instance is compensated for by an increase in insulin secretion [1]. However, in some individuals the beta cell compensatory response to insulin resistance fails or is insufficient, resulting in hyperglycaemia. Since hyperglycaemia itself is damaging to the beta cell, its emergence sets up a vicious cycle of increasing glycaemia and deteriorating beta cell function. While a number of causes of beta cell dysfunction have been suggested, including glucose toxicity, lipotoxicity and amyloid deposition, the mechanisms involved are not fully understood. In this article we propose that, paradoxically, an important mechanism contributing to beta cell failure in type 2 diabetes is the ability to hypersecrete insulin. Thus, a characteristic that in the early stages of the 
disease is beneficial in the maintenance of normal glucose tolerance, in itself leads to the more rapid demise of the beta cell and development of frank diabetes. This topic will be explored by addressing three simple questions:

1. Is there evidence that insulin hypersecretion can precede beta cell dysfunction?

2. Can primary (genetic) insulin hypersecretion result in diabetes?

3. If insulin hypersecretion is reduced, can beta cell function be improved in diabetes?

In the remainder of the article, some of the mechanisms that may be responsible for hypersecretion-induced beta cell dysfunction will be discussed.

Can insulin hypersecretion precede beta cell dysfunction and diabetes? Insulin hypersecretion can be secondary to the presence of insulin resistance; however, studies on obese individuals have shown that insulin hypersecretion can also occur independent of insulin resistance [2]. Specifically this study showed that insulin resistance was present in $34 \%$ of European white individuals with a BMI of $30-35 \mathrm{~kg} / \mathrm{m}^{2}$, while insulin hypersecretion was present in $49 \%$ of these individuals. This finding is supported by a study on juvenile obesity showing that post-meal increases in insulin release were more frequent and of greater amplitude in obese children compared with normal-weight children and preceded any changes in insulin sensitivity [3]. These studies raise the possibility that insulin resistance may not be the only mechanism responsible for insulin hypersecretion, and that there may be other signals involved in these obese individuals. In support of this, a variant in SURI resulting in elevated fasting and glucose-induced plasma insulin concentrations has been described in non-diabetic Mexican Americans, an ethnic group with a high incidence of type 2 diabetes [4]. A follow-up study showed that this same allelic variation in SUR1 was associated with type 2 diabetes in French white individuals [5], which may further support the notion of a causal link between insulin hypersecretion and the development of diabetes. Importantly, a study in Pima Indians, who have the highest incidence of diabetes of any ethnic group in the world, showed that fasting hyperinsulinaemia was a significant predictor of the disease, with individuals demonstrating fasting plasma insulin levels above the 90th percentile having a sixfold higher risk of developing diabetes compared with individuals in the lowest 10th percentile, independent of insulin resistance [6]. This suggests that insulin hypersecretion is not only an adaptive response to insulin resistance, but may also be a primary defect.

The capacity to hypersecrete insulin is detrimental to the beta cell irrespective of the insult that causes the major damage, as exemplified by the fact that insulin hypersecre- tion may also predispose individuals to type 1 diabetes. One study showed that HLA identical siblings of patients with type 1 diabetes have an exaggerated acute-phase insulin secretory response to both glucose and arginine compared with matched controls [7], leading the authors to hypothesise that increased beta cell activity may predispose the beta cells to damage by environmental factors. Furthermore, a widely used model of type 1 diabetes, the NOD mouse, displayed increased insulin secretion in response to an intraperitoneal injection of glucose as early as 4 weeks of age, i.e. in the prediabetic stage [8]. Finally, first-degree relatives of type 1 diabetes probands who progressed to diabetes were shown to have insulin hypersecretion as well as insulin resistance [9]. This observation has been supported by a recent study showing that individuals with a moderate or high risk were more likely to progress to type 1 diabetes if they were relatively insulin resistant [10]. Thus, these studies suggest that insulin hypersecretion may also be an important factor in the progression to beta cell failure in type 1 diabetes.

Can a primary defect causing insulin hypersecretion lead to beta cell dysfunction and diabetes? Evidence for a link between primary insulin hypersecretion and beta cell dysfunction comes from studies in patients with persistent hyperinsulinaemic hypoglycaemia of infancy (PHHI), who have genetic mutations causing overt insulin hypersecretion. In a family whose members had PHHI resulting from a mutation in the $G C K$ that lowers the $K_{\mathrm{m}}$ for glucose from 8.4 to $2.9 \mathrm{mmol} / \mathrm{l}$, an older member developed diabetes requiring insulin at the age of 48 years [11]. Diabetes has also been linked to another activating mutation in $G C K$ that causes neonatal hyperinsulinaemic hypoglycaemia [12]. Furthermore, a mutation in $H N F 4 A$ associated with macrosomia and mild hyperinsulinaemic hypoglycaemia in infancy also resulted in diabetes in five out of a total of eight mutant carriers by the age of 14 years [13] Similarly, nine out of eleven individuals of a large Finnish pedigree with a defect in SURI characterised by PHHI developed diabetes or impaired glucose tolerance in the face of normal insulin sensitivity [14]. In fact, in this latter study the authors suggested that this autosomal dominant mutation in SUR1 causing congenital hyperinsulinaemia followed by insulindeficient diabetes be considered as a new genetic subclass of type 2 diabetes with similar phenotypes of glucose intolerance, beta cell dysfunction and hyperglycaemia.

We have recently completed a 7-year study on the DBA/2 mouse, a strain that is susceptible to beta cell failure and diabetes when genetically stressed with obesity [15] or exposed to a high-glucose environment $[16,17]$. We found that in contrast to C57BL/6 mice, which have a genetic disruption in Nnt, and the 129T2 mice, which show low levels of expression, the diabetes-susceptible DBA/2 mice 
show a fivefold overexpression of this gene, which encodes the mitochondrial proton pump known as nicotinamide nucleotide transhydrogenase. Insulin secretion was elevated in DBA/2 mice relative to that in C57BL/6 and $129 \mathrm{~T} 2$ mice [18-20] Interestingly, we found that other strains of mice (BALB/c, FVB/N) that have previously been shown to be susceptible to diabetes when subjected to genetically induced obesity and insulin resistance also displayed increased NNT activity. We suggest that reduced NNT levels in the C57BL/6 and 129T2 strains result in lowered insulin secretion and mild glucose intolerance [21], and that protection against the development of diabetes in response to genetically induced obesity and insulin resistance may paradoxically be due to a reduced ability of the beta cell to secrete insulin. Consistent with this, we argue that a primary ability to hypersecrete insulin, as seen in DBA/2, FVB/N and $\mathrm{BALB} / \mathrm{c}$ mice, may predispose to beta cell dysfunction. This increased ability to hypersecrete insulin may also precipitate diabetes, at least in some individuals and ethnic groups, by mechanisms that will be discussed below.

Does reducing insulin secretion improve beta cell function in diabetes? Treatment with the insulin secretion inhibitor diazoxide prevents impairment of beta cell function in rats administered a $48 \mathrm{~h}$ glucose infusion [22], in $90 \%$ pancreatectomised diabetic rats [23] and in streptozotocintreated rats [24]. Furthermore, treatment of patients with type 2 diabetes with diazoxide or somatostatin resulted in improved glucagon- and tolbutamide-induced insulin secretion [25] and restored insulin pulsatility and the insulin/ proinsulin ratio in vitro [26]. Recently, Accili and colleagues suggested that protection against hyperglycaemia and oxidative stress could be afforded to beta cells as a result of increased levels of the forkhead protein Foxo1, which can lead to a concerted repression of genes involved in glycolysis, nitric oxide synthesis, G-protein-coupled receptor signalling and ion transport [27]. This general reduction in cellular metabolism was termed 'metabolic diapause', and was hypothesised to provide protection as a result of beta cell rest. This suggests that allowing beta cell rest by reducing insulin secretion could be beneficial and could protect against glucose toxicity and oxidative stress.

\section{Possible mechanisms that could explain hypersecretion-induced beta cell dysfunction}

Exactly how hypersecretion of insulin could lead to overt diabetes is not known. The beta cell could be simply exhausted by the prolonged need to hypersecrete insulin or be compromised by stress responses caused by the need to produce and secrete excessive amounts of insulin. In the following section we will explore the possibility that the increased demand for insulin production could overload the endoplasmic reticulum (ER). Alternatively, the increased glycolytic flux required for increased insulin secretion could result in oxidative stress. Both these stresses would be expected to damage the beta cell and contribute to the defects in insulin secretion seen in diabetes.

ER stress The ER is where proteins are folded into their native conformation and post-translationally modified. Proteins that have been correctly folded proceed to the Golgi apparatus, whereas incorrectly folded proteins remain in the ER for either re-folding or degradation. Disruption of any of these processes, such as an overload of protein synthesis, results in ER stress and induces the unfolded protein response. Because of its function as a secretory cell, the beta cell is characterised by a highly developed ER and high levels of ER stress transducer proteins, including inositol requirement 1 (IRE1), RNAdependent protein kinase-like ER kinase (PERK) and immunoglobulin heavy chain binding protein (BiP). Studies have shown that the beta cell is one of the most susceptible cells to ER stress, and furthermore, ER stress-mediated apoptosis in the beta cell has been suggested as having an important role in the development of type 2 diabetes [28, 29]. In fact, diabetes has been labelled by some as a protein misfolding disease [30], indicating the substantial responsibility the ER has in the correct functioning of the beta cell.

Details of how ER stress is induced and its effects on cellular function have been well reviewed recently [31, 32] and are beyond the scope of this debate. However, it is important to highlight the following studies that are pertinent to this discussion regarding beta cell dysfunction and diabetes. Genetic evidence that ER stress can lead to diabetes is provided by two rare syndromes: (1) WolcottRallison syndrome of infantile diabetes, caused by a mutation in PERK [33]; and (2) Wolfram syndrome, characterised by juvenile diabetes and optic atrophy, resulting from mutations in WFS1, which codes for a transmembrane glycoprotein that serves as an ER calcium channel [34]. Further support for a role of ER stress in diabetes was presented in mice with genetic ablation of PERK or the chaperone $\mathrm{P} 58^{\mathrm{IPK}}$ that resulted in islet beta cell death and hyperglycaemia [35, 36]. Moreover, a recent study has shown that in the Akita mouse model of diabetes, a mutation in Ins 2 resulted in misfolding of the insulin protein causing ER stress and beta cell apoptosis [37]. Chronic exposure of islets and beta cells to fatty acids is known to cause dysfunction and cellular death [38], and this apoptosis has recently been shown to be the result of activation of an ER stress response [39-41]. Interestingly, ER stress markers have also been shown to be increased in islets from patients with type 2 diabetes [41, 42], implicating ER stress as a contributor to beta cell dysfunction in humans. 
The above studies provide evidence that induction of ER stress can cause beta cell dysfunction and death and contribute to diabetes. It is therefore conceivable that, in the presence of an underlying (genetic) propensity for ER stress (see Fig. 1), increased pressure on the beta cell to secrete more insulin, whether induced by obesity/insulin resistance or chemical means (e.g. sulfonylureas), may cause beta cell death.

Oxidative stress Oxidative stress results when the formation and clearance of reactive oxygen species (ROS) is unbalanced. The normal function of the mitochondrial respiratory chain involves the passing of electrons between enzyme complexes. This process is not, however, failsafe, as a significant proportion of these electrons 'leak', resulting in the generation of free radicals (or unpaired electrons) [43]. When these radicals react with oxygen, ROS are produced, which are extremely toxic to cells, causing DNA and cell membrane damage as well as promoting the formation of lipid peroxides [44]. Consequently, there is a decline in mitochondrial operations including decreased ATP synthesis, dysregulated calcium homeostasis and, ultimately, cell death [44].

To thwart the damaging effects of oxidative stress the mitochondrion contains many enzymes, known as antioxidants, which can convert the ROS into harmless derivatives. Interestingly, the beta cell is especially sensitive to oxidative

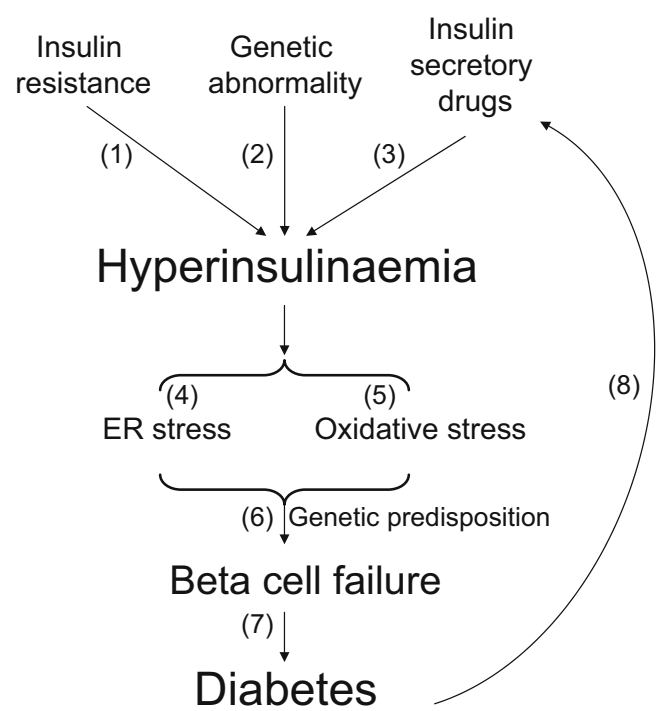

Fig. 1 Schematic diagram showing how hyperinsulinaemia could contribute to diabetes. A state of hyperinsulinaemia could be caused by (1) increased insulin demand (insulin resistance); (2) a genetic abnormality leading to hypersecretion; or (3) the use of insulin secretory drugs. The ensuing hyperinsulinaemia could then induce ER (4) or oxidative (5) stress. In individuals with a genetic predisposition, this increased stress could lead to beta cell failure (6) and, thereby, diabetes (7). The treatment of diabetes with insulin secretory drugs (8) could further promote insulin hypersecretion, leading to worsening of beta cell function stress owing to its low levels of antioxidant enzymes [45], and so the balance between free radical production and detoxification could easily be thrown in the direction of oxidative stress. Incubation of islets or beta cells in high glucose and NEFA has been shown to cause impaired insulin secretion, which can be improved with antioxidant treatment [46, 47]. Increased markers of oxidative stress have also been measured in islets from patients with type 2 diabetes, and improvements were seen when the islets were treated with the antioxidant glutathione [48]. Our own work has shown that islets from the DBA/2 mouse, a strain susceptible to diabetes, hypersecrete insulin in the normal 'non-stressed' state (as discussed earlier) but are susceptible to oxidative stress induced by high glucose, which is associated with impaired insulin secretion [17]. Therefore, there is experimental evidence to suggest that an ability to hypersecrete insulin may increase the amount of ROS generated, causing oxidative stress that would in turn damage the beta cell and contribute to diabetes.

\section{Clinical consequences}

Does this debate have clinical consequences? If the hypothesis that hypersecretion contributes to the progressive destruction of the beta cell is correct, it would have major implications for how type 2 diabetes should be treated. Perhaps the most compelling results suggesting a need for a change in practice have come from the a Diabetes Outcome Progression Trial (ADOPT) [49]. In this study, the clinical endpoint was failure of monotherapy drug treatment as reflected by a fasting plasma glucose level of greater than $10 \mathrm{mmol} / \mathrm{l}$ in newly diagnosed patients with type 2 diabetes. The drugs used were the sulfonylurea glibenclamide (known as glyburide in the USA and Canada), the biguanide metformin and the thiazolidinedione rosiglitazone. The results were clear: within the first 6 months, glibenclamide had the strongest effect in reducing plasma glucose and $\mathrm{HbAlc}$ levels. Thereafter, the glibenclamide treatment group had the greatest increase in both plasma glucose and $\mathrm{HbA}_{1 \mathrm{c}}$ levels such that, at the 4 year evaluation, $74 \%$ of the patients in the glibenclamide group had an $\mathrm{HbA}_{1 \mathrm{c}}$ level greater than $7 \%$, compared with 60 and $64 \%$ of patients in the rosiglitazone and metformin treatment groups, respectively. Alarmingly, the frequency of failure of monotherapy treatment at 5 years was 34\% for glibenclamide-treated patients, while this was only $21 \%$ and $15 \%$ for the metformin and rosiglitazone groups, respectively. In other words, treating newly diagnosed type 2 diabetic patients with the insulin secretagogue glibenclamide resulted in higher plasma glucose levels and an increased rate of failure of monotherapy treatment compared with the insulin sensitisers metformin and rosiglita- 
zone. In vitro studies support this finding, showing that chronic treatment of beta cells with sulfonylureas can cause cell death via apoptosis [50]. This suggests that, in an environment of beta cell stress, as a result of obesity and insulin resistance, the increased pressure by a sulfonylurea to secrete even more insulin further harms the beta cell.

\section{Conclusion}

In conclusion, we argue that under conditions of nutrient excess (obesity/high fat intake, increased glycaemia), an increased ability to metabolise nutrients is detrimental to beta cell survival by activating mechanisms of ER and/or oxidative stress (Fig. 1). The inescapable conclusion is that treatment with agents that stimulate insulin secretion, such as sulfonylureas, should be delayed as long as possible. In many countries, sulfonylureas are used as a first- or secondline therapy. Given that accumulating experimental data suggest that such treatments may be detrimental to beta cell function, we urge that this issue be resolved by further clinical studies on the long-term outcomes of sulfonylurea use.

Acknowledgements Work mentioned in this article has been funded by the National Health and Medical Research Council of Australia and Diabetes Australia Research Trust fund. S. Andrikopoulos is a recipient of the R. D. Wright Biomedical Career Development Award form the National Health and Medical Research Council of Australia.

Duality of interest The authors declare that there is no duality of interest associated with this manuscript.

\section{References}

1. Bailey CJ (1999) Insulin resistance and antidiabetic drugs. Biochem Pharmacol 58:1511-1520

2. Ferrannini E, Natali A, Bell P, Cavallo-Perin P, Lalic N, Mingrone G (1997) Insulin resistance and hypersecretion in obesity. J Clin Invest 100:1166-1173

3. Le Stunff C, Bougneres P (1994) Early changes in postprandial insulin secretion, not in insulin sensitivity, characterize juvenile obesity. Diabetes 43:696-702

4. Goksel DL, Fischbach K, Duggirala R et al (1998) Variant in sulfonylurea receptor-1 gene is associated with high insulin concentrations in non-diabetic Mexican Americans: SUR-1 gene variants and hyperinsulinemia. Hum Genet 103:280-285

5. Reis AF, Ye WZ, Dubois-Laforgue D, Bellanne-Chantelot C, Timsit J, Velho G (2000) Association of a variant in exon 31 of the sulfonylurea receptor 1 (SUR1) gene with type 2 diabetes mellitus in French Caucasians. Hum Genet 107:138-144

6. Weyer C, Hanson RL, Tataranni PA, Bogardus C, Pratley RE (2000) A high fasting plasma insulin concentration predicts type 2 diabetes independent of insulin resistance. Evidence for a pathogenic role of relative hyperinsulinemia. Diabetes 49:2094-2101
7. Hollander PH, Asplin CM, Kniaz D, Hansen JA, Palmer JP (1982) Beta-cell dysfunction in nondiabetic HLA identical siblings of insulin-dependent diabetics. Diabetes 31:149-153

8. Amrani A, Durant S, Throsby M, Coulaud J, Dardenne M, Homo-Delarche F (1998) Glucose homeostasis in the nonobese diabetic mouse at the prediabetic stage. Endocrinology 139: $1115-1124$

9. Fourlanos S, Narendran P, Byrnes GB, Colman PG, Harrison LC (2004) Insulin resistance is a risk factor for progression to type 1 diabetes. Diabetologia 47:1661-1667

10. Xu P, Cuthbertson D, Greenbaum C, Palmer JP, Krischer JP (2007) Role of insulin resistance in predicting progression to type 1 diabetes. Diabetes Care 30:2314-2320

11. Glaser B, Kesavan P, Heyman M et al (1998) Familial hyperinsulinism caused by an activating glucokinase mutation. N Engl J Med 338:226-230

12. Christesen HB, Jacobsen BB, Odili S et al (2002) The second activating glucokinase mutation (A456V): implications for glucose homeostasis and diabetes therapy. Diabetes 51:1240-1246

13. Pearson ER, Boj SF, Steele AM et al (2007) Macrosomia and hyperinsulinaemic hypoglycaemia in patients with heterozygous mutations in the HNF4A gene. PLoS Med 4:e118

14. Huopio H, Otonkoski T, Vauhkonen I, Reimann F, Ashcroft FM, Laakso M (2003) A new subtype of autosomal dominant diabetes attributable to a mutation in the gene for sulfonylurea receptor 1 . Lancet 361:301-307

15. Leiter EH, Coleman DL, Hummel KP (1981) The influence of genetic background on the expression of mutations at the diabetes locus in the mouse. III. Effect of H-2 haplotype and sex. Diabetes 30:1029-1034

16. Kooptiwut S, Kebede M, Zraika S et al (2005) High glucoseinduced impairment in insulin secretion is associated with reduction in islet glucokinase in a mouse model of susceptibility to islet dysfunction. J Mol Endocrinol 35:39-48

17. Zraika S, Aston-Mourney K, Laybutt DR et al (2006) The influence of genetic background on the induction of oxidative stress and impaired insulin secretion in mouse islets. Diabetologia 49:1254-1263

18. Kooptiwut S, Zraika S, Thorburn AW et al (2002) Comparison of insulin secretory function in two mouse models with different susceptibility to beta-cell failure. Endocrinology 143:2085-2092

19. Andrikopoulos S, Massa CM, Aston-Mourney K et al (2005) Differential effect of inbred mouse strain (C57BL/6, DBA/2, 129T2) on insulin secretory function in response to a high fat diet. J Endocrinol 187:45-53

20. Aston-Mourney K, Wong N, Kebede M et al (2007) Increased nicotinamide nucleotide transhydrogenase levels predispose to insulin hypersecretion in a mouse strain susceptible to diabetes. Diabetologia 50:2476-2485

21. Toye AA, Lippiat JD, Proks P et al (2005) A genetic and physiological study of impaired glucose homeostasis control in C57BL/6J mice. Diabetologia 48:675-686

22. Sako Y, Grill VE (1990) Coupling of $\beta$-cell desensitization by hyperglycemia to excessive stimulation and circulating insulin in glucose-infused rats. Diabetes 39:1580-1583

23. Leahy JL, Bumbalo LM, Chen C (1994) Diazoxide causes recovery of $\beta$-cell glucose responsiveness in $90 \%$ pancreatectomized diabetic rats. Diabetes 43:173-179

24. Kullin M, Li Z, Hansen B, Bjork E, Sandler S, Karlsson FA (2000) $\mathrm{K}_{\text {ATP }}$ channel openers protect rat islets against the toxic effect of streptozotocin. Diabetes 49:1131-1136

25. Greenwood RH, Mahler RF, Hales CN (1976) Improvement in insulin secretion in diabetes after diazoxide. Lancet i:444-447

26. Laedtke T, Kjems L, Porksen N et al (2000) Overnight inhibition of insulin secretion restores pulsatility and proinsulin/insulin ratio in type 2 diabetes. Am J Physiol 279:E520-E528 
27. Buteau J, Shlien A, Foisy S, Accili D (2007) Metabolic diapause in pancreatic beta-cells expressing a gain-of-function mutant of the forkhead protein Foxo1. J Biol Chem 282:287-293

28. Oyadomari S, Araki E, Mori M (2002) Endoplasmic reticulum stressmediated apoptosis in pancreatic beta-cells. Apoptosis 7:335-345

29. Araki E, Oyadomari S, Mori M (2003) Endoplasmic reticulum stress and diabetes mellitus. Intern Med 42:7-14

30. Wiseman RL, Balch WE (2005) A new pharmacology — drugging stressed folding pathways. Trends Mol Med 11:347-350

31. Cnop M, Welsh N, Jonas JC, Jorns A, Lenzen S, Eizirik DL (2005) Mechanisms of pancreatic beta-cell death in type 1 and type 2 diabetes: many differences, few similarities. Diabetes 54 (Suppl 2):S97-S107

32. Marciniak SJ, Ron D (2006) Endoplasmic reticulum stress and signaling in disease. Physiol Rev 86:1133-1149

33. Delepine M, Nicolino M, Barrett T, Golamaully M, Lathrop GM, Julier C (2000) EIF2AK3, encoding translation initiation factor 2alpha kinase 3, is mutated in patients with Wolcott-Rallison syndrome. Nat Genet 25:406-409

34. Riggs AC, Bernal-Mizrachi E, Ohsugi M et al (2005) Mice conditionally lacking the Wolfram gene in pancreatic islet beta cells exhibit diabetes as a result of enhanced endoplasmic reticulum stress and apoptosis. Diabetologia 48:2313-2321

35. Harding HP, Zeng H, Zhang Y et al (2001) Diabetes mellitus and exocrine pancreatic dysfunction in perk $-/-$ mice reveals a role for translational control in secretory cell survival. Mol Cell 7:1153-1163

36. Ladiges WC, Knoblaugh SE, Morton JF et al (2005) Pancreatic beta-cell failure and diabetes in mice with a deletion mutation of the endoplasmic reticulum molecular chaperone gene P58IPK. Diabetes 54:1074-1081

37. Nozaki J, Kubota H, Yoshida H et al (2004) The endoplasmic reticulum stress response is stimulated through the continuous activation of transcription factors ATF6 and XBP1 in Ins2+/Akita pancreatic beta cells. Genes Cells 9:261-270

38. Prentki M, Nolan CJ (2006) Islet beta cell failure in type 2 diabetes. J Clin Invest 116:1802-1812
39. Kharroubi I, Ladriere L, Cardozo AK, Dogusan Z, Cnop M, Eizirik DL (2004) Free fatty acids and cytokines induce pancreatic beta-cell apoptosis by different mechanisms: role of nuclear factor-kappaB and endoplasmic reticulum stress. Endocrinology 145:5087-5096

40. Pirot P, Ortis F, Cnop M et al (2007) Transcriptional regulation of the endoplasmic reticulum stress gene chop in pancreatic insulinproducing cells. Diabetes 56:1069-1077

41. Laybutt DR, Preston AM, Akerfeldt MC et al (2007) Endoplasmic reticulum stress contributes to beta cell apoptosis in type 2 diabetes. Diabetologia 50:752-763

42. Huang CJ, Lin CY, Haataja L et al (2007) High expression rates of human islet amyloid polypeptide induce endoplasmic reticulum stress mediated beta-cell apoptosis, a characteristic of humans with type 2 but not type 1 diabetes. Diabetes 56:2016-2027

43. Chance B, Sies H, Boveris A (1979) Hydroperoxide metabolism in mammalian organs. Physiol Rev 59:527-605

44. James AM, Murphy MP (2002) How mitochondrial damage affects cell function. J Biomed Sci 9:475-487

45. Lenzen S, Drinkgern J, Tiedge M (1996) Low antioxidant enzyme gene expression in pancreatic islets compared with various other mouse tissues. Free Radic Biol Med 20:463-466

46. Oprescu AI, Bikopoulos G, Naassan A et al (2007) Free fatty acidinduced reduction in glucose stimulated insulin secretion: evidence for a role of oxidative stress in vitro and in vivo. Diabetes 56:2927-2937

47. Tang C, Han P, Oprescu AI et al (2007) Evidence for a role of superoxide generation in glucose-induced beta-cell dysfunction in vivo. Diabetes 56:2722-2731

48. Del Guerra S, Lupi R, Marselli L et al (2005) Functional and molecular defects of pancreatic islets in human type 2 diabetes. Diabetes 54:727-735

49. Kahn SE, Haffner SM, Heise MA et al (2006) Glycemic durability of rosiglitazone, metformin, or glyburide monotherapy. N Engl J Med 355:2427-2443

50. Maedler K, Carr RD, Bosco D, Zuellig RA, Berney T, Donath MY (2005) Sulfonylurea induced beta-cell apoptosis in cultured human islets. J Clin Endocrinol Metab 90:501-506 